\title{
Early-onset generalized limb-onset dystonia
}

INSERM

\section{Source}

INSERM. (1999). Orphanet: an online rare disease and orphan drug data base. Early-onset generalized limb-onset dystonia. ORPHA:256

A rare movement disorder characterized by involuntary, repetitive, sustained muscle contractions or postures that typically beg ins in a single limb and, in most individuals, followed by progressive involvement of other limbs and the trunk, typically sparing the cranial and cervical region. 